\title{
Behaviors of Personal Meaning Marker Suffixes in Mandarin Language
}

\author{
Subandi Subandi ${ }^{1, *}$ Xiao Renfei ${ }^{2}$ Muhammad F. Masrur ${ }^{3}$ Cicik Arista ${ }^{4}$ \\ ${ }^{1,3,4}$ Mandarin Education Program, Universitas Negeri Surabaya, Indonesia \\ ${ }^{2}$ Teaching Chinese as a Foreign Language, Central China Normal University, Wuhan, China \\ *Corresponding author. Email: subandi@unesa.ac.id
}

\begin{abstract}
Suffixes are constituents that form larger grammatical units, especially in the form of words. Each suffix has a specific function in forming the meaning type: the personal meaning type. Various suffixes form a single personal meaning in Mandarin, and each form has its specifications of personal meaning and behavior. The specifications of the personal meaning built by each suffix include (1) a person who has expertise in science, (2) a person as a member and/or part of a group or organization, (3) personal who has knowledge and skills, (4) a person with military specifications, trained person, (5) a person with the type of hard worker, and (6) a person with non-permanent or temporary activities. Due to these behavioral specifications, not all verb morphemes can be followed by suffixes that form personal meaning. Between suffixes forming personal meaning and morpheme verbs have their criteria. As a result, both are bound by the criteria and specifications of each suffix's semantic function to form personal meaning in the grammatical unit of the word class. The scope of personal meaning built is limited and bound by the lexical meaning of verb morpheme elements followed by suffixes.
\end{abstract}

Keywords: Derivational affix, Suffix behavior, Constituent, Personal meaning, Frozen bond.

\section{INTRODUCTION}

Affixation process is a universal phenomenon that can be found in almost every language in the world. Although every language has characteristics as an identity, but in general, many languages in the world have affixation phenomena. Affixation is the process of adding an affix to a basic morpheme to form a more complex level. Affixation consists of two types, one of which is derivation. Derivational affix is an affixation process that can form new types of words and/or can change meaning. This type of affixation can be found in almost all languages. However, the types of affixes and the process of affixation to form the same meaning are highly different. In this case, each language has its own characteristics. This is the same as Mandarin language which only has two types of affixes, namely prefixes (前 讯 qiánzhui) and suffixes (后讯 hòuzhui) (Feng, 2006: 43; Zhao, 1967: 67; Yán, 2019: 19). Furthermore, related to the affixation process, especially derivational affix, it can be seen in the process of word formation which refers to personal meaning. In this case, Mandarin language involves suffix elements and the suffix types involved also vary [1]-[3]. For example, to refer to a personal meaning that has an element of meaning expertise in science will be marked by the use of the suffix $\{\sim$ 师 - shi $\}$. To form a personal meaning, the suffix $\{\sim$ 师-shi $\}$ must be placed after another morpheme, such as, morpheme \{ 老lăo\} 'experience' becomes \{老师 lăoshī\} which means 'teacher' where changes occur in the aspect of meaning. Furthermore, if the suffix $\{\sim$ 师 $-s h i\}$ is added after the morpheme \{ 教 jiāo- $\}$ 'teach' indicating a verb, it becomes \{教师 jiāoshī 'teacher'. In this case, other than changing the meaning, the type of word also changes from a verb to a noun. Then, the morpheme 律 lì 'law', if the suffix \{ 师 -shi \} is added after it, it becomes 律师 lüshī 'lawyer'. Taking into account the three examples above, the affixation process involving the suffix 师 shi can change the meaning of the basic morpheme into a personal meaning. On the other hand, to form a personal meaning that has an element of member or personal meaning that works in a certain part, the suffix $\{\sim$ 员 -yuan $\}$ must be used. The suffix $\{\sim$ 员 -yuan $\}$ is placed after the morpheme 演 yăn 'stage; show', it becomes 演员 yănyuán 'player'. Even 
though the suffix $\{\sim$ 师 - shi $\}$ and suffix $\{\sim$ 员 -yuan $\}$ have the same function to form personal meaning, it does not mean that they can be used interchangeably, such as (*t 员 lăoyuan), (*教员 jiāoyuan), (*律员 lüyuan) or vice versa (*演师 yănsh $\vec{\imath}$ ). Based on the rules of Mandarin morphology, the structure of these units is unacceptable [4]-[6]. This shows that there are indications of different behavior between each type of suffix that forms personal meaning in Mandarin language.

However, as has been noted above that not all languages have the same affixation phenomenon as in Mandarin. One of them is in Indonesian. The personal meaning that is formed through the affixation process, especially involving elements of the basic morpheme is a verb. It does not use suffix elements, but uses one prefix element, namely prefix $(\sim$ pe). Although in the process of affixation the prefix $(\sim$ pe) undergoes an assimilation process (not found in Mandarin language), that is, with all kinds of form assimilation according to Indonesian morphological rules, the main element forming personal meaning is derived from the prefix $(\sim$ pe).

The explanation above proves that every language has a linguistic phenomenon that is universal, a phenomenon that is generally shared by most languages and/or by all languages in the world. However, there are not a few linguistic phenomena that are specific and function as identity markers since they are only owned by certain languages. Based on the description above, this article does not aim to make a comparison or contrast between Mandarin language and Indonesian. This study aims to describe the behavior of suffixes forming personal meaning through the derivational affix process and the characteristics of the types of verb morphemes that can be followed by the suffix elements forming personal meaning in Mandarin language. This description of the affixation phenomenon in Indonesian is only used as a description and introductory information regarding the differences in the formation of personal meaning through the affixation process between the two languages. In addition, based on the results of the previous studies analysis, there are no results that indicate the existence of specific criteria along with a description of the behavior of suffixes forming personal meaning and the criteria for morpheme verbs that can be followed. Due to the many types of suffixes forming pesonal meanings in Mandarin language, the discussion of this study is limited to suffixes $\{\sim$ 者 $-z h \breve{e}\},\{\sim$ 师 $-s h \bar{l}\},\{\sim$ 兵 - bìng $\},\{\sim$ 员-yuán $\},\{\sim \pm-$ shì $\},\{$ 工 $-g \bar{o} n g\}$, and $\{\sim$ 手-shŏu $\}$. These limitations are due to two things, namely (1) to maintain the validity of the data is limited, namely, one type of data must be more than three data and (2) because the suffixes studied in this study have a fairly high frequency of occurrence or use. This can be proven by the number of each type of suffix amounting to at least 9 data.

\subsection{Suffix}

Suffix is one type of affix that is placed after the morpheme that is followed. Suffixes are also a form of bound morpheme since suffixes are constituents of larger grammatical units, especially words [7], [8]. In Mandarin language, there are many types of suffixes that have universal characteristic, namely, as constituents to form larger units in the form of words. For example, the bound morpheme in the form of the suffix $\sim$ 儿 $\{-e r\}$ already has a semantic function, namely, to form meanings related to the impression of being interesting and funny. However, it cannot be used independently and the meaning cannot be obtained if the suffix $\{-e r\}$ stands alone [9], [10]. The semantic function will only be formed if it is placed behind another morpheme, such as the morpheme 画 huà 'paint; draw' and add the suffix 〜 $\{-e r\}$. Then, it will become 画儿 huàr 'painting; description'. Like the general characteristics of suffixes, suffixes in Mandarin language can also be attached to various types of words, either behind verbs, adjectives or nouns. Due to the various types, the types of meanings built by each suffix types in Mandarin language also vary. One of them is personal meaning. The forms of suffixes that can build personal meanings in Mandarin language, including the suffixes $\{\sim$ 者 $-z h \breve{e}\},\{\sim$ 师 $-s h \bar{l}\},\{\sim$ 兵 - bìng $\},\{\sim$ 员-yuán $\},\{\sim \pm-$ shì $\},\{\sim-g \bar{o} n g\}$, and $\{\sim$ 手-shŏu $\}$. Although the forms of these suffixes are not the same, all of them are suffixes that can form elements of personal meaning. The distinguishing aspect lies in the type of personal meaning that is constructed. Therefore, even though all of them become elements that form personal meaning, it does not mean that the same morpheme can be used by all of these suffixes. For example, in the morpheme \{ 教 jiāo- $\}$ 'teach', in order to form personal meaning, it will only be followed by the suffix $\{\sim$ 师 $-s h \bar{l}\}$ so that the grammatical unit of the word class $\{$ 教师 jiāoshī 'teacher' is formed. The grammatical unit will not be accepted if the suffix element $\{\sim$ 师 $-s h \bar{l}\}$, for example, is replaced with another suffix, such as $\{\sim$ 者 $-z h \breve{e}\}$ so that it becomes $\{*$ 教者 jiāozhe $\}$ or with the suffix $\{\sim$ 家 $-j i \bar{a}\}$ so that the unit will be obtained $\{$ *教家 jiāojia $\}$. Based on the morphological rules of Mandarin language, these units are unacceptable [11]. This proves that each suffix that functions as an element forming the personal meaning has a different specification of personal meaning. Therefore, each suffix that forms personal meaning cannot follow every morpheme, especially the type of verb morpheme since it is limited by the specification of the type of personal meaning possessed by each suffix. This means that each suffix will determine the type of verbal morpheme that 
will be followed according to the specifications of the personal meaning it has.

\section{METHODS}

This research is a type of qualitative research with a description method. The data of this study are in the form of words that have personal meanings with elements forming verb morphemes and suffix elements forming personal meanings. The total number of data is 98 data which is then classified as in Table 1. After the data is classified and identified, the next step is to analyze and describe it to get a real and concrete description of the behavior and data criteria.

Table 1. Data and classification

\begin{tabular}{|l|l|l|l|l|l|l|l|}
\hline $\begin{array}{l}\text { Suffix } \\
\text { Types }\end{array}$ & $\sim$ 者 & 师 & $\sim$ 员 & $\sim$ 手 & $\sim \pm$ & $\sim$ 工 & $\sim$ 兵 \\
\hline $\begin{array}{l}\text { Exam } \\
\text { ple }\end{array}$ & 记者 & 师 & 演员 & 助手 & 骑士 & 劳工 & 骑兵 \\
\hline Total & 21 & 3 & 16 & 16 & 10 & 13 & 9 \\
\hline
\end{tabular}

\section{RESULTS AND DISCUSSION}

\subsection{Suffix $\{\sim$ 者-zhĕ $\}$}

Suffix $\{\sim$ 者-zhě $\}$ has a semantic function to form personal meanings whose meaning specifications are broader and more general than other types of suffixes. This is because when viewed from the character of the letters, these suffixes already have the basic meaning of people. Therefore, the nature of using the suffix \{ 者 $z h \check{\}}\}$ is looser. Although it does not mean that it can be combined with all types of verb morphemes, the possibility of being included in verb morphemes is more open and does not have the nature of frozen bond. Thus, when compared with other types of personal meaningforming suffixes, the quantitative data of the suffix $\{\sim$ 者

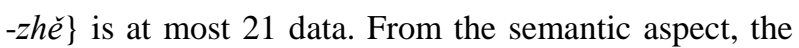
meaning of the suffix $\{\sim$ 者 $-z h e ̌\}$ is a person who have professions and work in certain fields. The following is an example of data that has a suffix forming element $\{\sim$ 者 $-z h e ̌\}$.

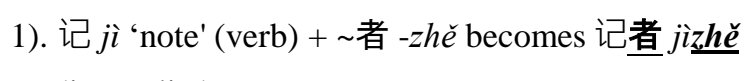
'journalist'.

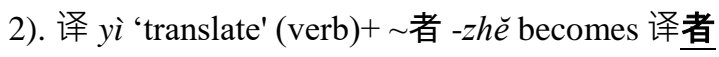
yizh $\underline{\underline{h e}}$ 'translator'.

\section{3). 作 zuò 'do' (verb)+ 者 -zhĕ becomes 作者 zuòzh $\underline{\text { he }}$ 'author or writer'.}

Based on the example above, all morphemes followed by the suffix $\{\sim$ 者 $-z h e \check{\}}$ are verb morphemes. The character of the lexical meaning possessed by each element of the verb morpheme varies. This proves that the suffix $\{\sim$ 者 $-z h \check{e}\}$ is more general and open. The meaning of the lexical element of the verb becomes the

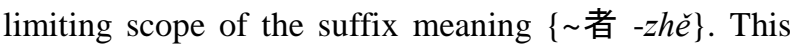
means that the type of personal meaning built has been determined by the meaning of the verb morpheme element, that is, the meaning of the doer that is constructed comes from the activity of the verb morpheme element.

\subsection{Suffix $\{\sim$ 师-shi $\}$}

The semantic function of the suffix $\{\sim$ 师 $-s h \bar{\imath}\}$ is to form a personal meaning that has qualifications. In addition, it also has knowledge and expertise in the field of science which is based on certain technical and theoretical concepts. Due to the special specifications possessed by the personal meaning, the elements of the verb morpheme that can be followed are limited by the specification of the meaning. The bonding of wordforming verb morpheme elements with the suffix $\{\sim$ 师 $s h \bar{l}\}$ is more special or frozen. The concept of specifying the meaning of the suffix $\{\sim$ 师 $-s h \bar{l}\}$ is also a limitation of the personal meaning scope that is built with the verb morpheme element. Some examples can be seen as follows.

1). 化妆 huàzhuāng 'makeup' (verb) + 师 $-s h \bar{\imath}$

becomes 化妆师 huàzhuāngshī 'makeup artist.

2). 摄影 shèyı̌ng 'photograph' (verb) + 师 $-s h \bar{\imath}$

becomes 摄影师 shèy̌ngshī 'photographer'.

3). 老 lăo 'experience' (verb) + 师 - shi becomes 老师

lăoshī 'teacher'.

Seen from the examples above, lexical meaning of the morpheme element of the verb acts as an ordinate element. While the element of the suffix $\{\sim$ 师 $-s h \bar{l}\}$ acts as an attribute, namely it provides a specification of personal meaning that has elements of knowledge meaning and certain theoretical or technical concepts.

\subsection{Suffix \{ 员-yuán\}}

The semantic function of the suffix $\{\sim$ 员-yuán $\}$ is to form a personal meaning with personal specifications 
who have certain skills and professions. This personality places more emphasis on performance aspects related to the service sector, talent in the arts and crafts, and those related to the world of performance. As a result, the semantic function of the suffix $\{\sim$ 员-yuán $\}$ is narrower and the nature of the relationship with verb morpheme elements is also more frozen. The specification of the sematic function of the suffix $\{\sim$ 员-yuán $\}$ has the function of binding personal meanings formed with verb morpheme elements so that the scope of the meaning area is also narrower. The following is an example of data regarding the use of the suffix $\{\sim$ 员-yuán $\}$ in word classes.

1). 演 yăn 'perform' (verb) + 员-yuán becomes 演员 yănyuán 'performer or artist'.

2). 服务 fúwù 'serve' (verb) + 员-yuán becomes 服务

员 fúwùyuán 'servant'.

3). 运动 yùndòng 'exercise' (verb) + 员-yuán becomes 运动员 yùndòngyuán 'athlete'.

It can be ascertained that the morpheme element of the verb that is added with the suffix $\{$ 员-yuán $\}$ is a type of verb that has the concept of lexical meaning. This is as required by the semantic function specification of the suffix \{ 员-yuán\}, which has meaning related to aspects of service, talent, and performance..

\subsection{Suffix $\{\sim$ 手-shŏu\}}

Independently, when the letter [手 shǒu] acts as a free morpheme, it has the basic meaning of 'hand'. However, when it functions as a suffix $\{\sim$ 手 - shou $\}$, the basic meaning of 'hand' is lost and cannot stand alone so that it no longer has meaning but turns into a semantic function.

The semantic function of the suffix $\{\sim$ 手 - shŏu $\}$ is to form a personal meaning who has expertise or is skilled in a particular field. This semantic function is almost the same as the semantic function of the suffix $\{\sim$ 员-yuán\}, but the suffix $\{\sim$ 手 - shŏ $\}$ emphasizes the skillful aspect which does not require scientific and similar aspects. Having and mastering knowledge or not, is not a provision in the suffix $\{\sim$ 手 - shou $\}$. Furthermore, the specification of this 'skilled' semantic function is limited in scope by the activity component of verb morpheme elements. The above description can be proven through the following sample data..
1). 助 zhù 'help' (verb) + 手 -shŏu becomes 助手 zhùsȟ̆u 'helper or assistant'.

2). 选 xuăn 'choose' (verb) + 手 -shŏu becomes 选手 xuănshŏu 'participant'.

\section{3). 扒 pá 'take' (verb) + 手 -shŏu becomes 扒手 páshǒu 'pickpocket'.}

Based on the sample data above, it is found that all the meanings constructed by the suffix $\{\sim$ 手 - shou $\}$ together with verb morpheme elements reflect as individuals who have skills related to verb element activities. This means that skilled personnel carry out verb element activities where expertise and skills are built as a result of habit, not built through certain theoretical knowledge or concepts.

\subsection{Suffix $\{\sim \pm-$ shi $\}$}

The suffix $\{\sim \pm-$ shi $\}$ also has a semantic function to form personal meaning with personal qualifications that have behaviors, abilities, and skills as a result of the process of practicing or being trained personally. The semantic classification of the suffix $\{\sim \pm-$ shi $\}$ is still under the expert criteria since the abilities possessed by the personal meaning are still at the level of being trained, not yet at the level of an expert. This semantic function specification is a differentiator with other personal meaning-forming suffixes. This interpretation can be proven by the following data examples.

1). 护 hù 'nurse' (verb) + 士 - shi becomes 护士 hùshì 'nurse'.

2). 骑 qí 'ride' (verb) + 士 -shi becomes 骑士 qíshì 'knight'.

\section{3). 讯 hù 'protect' (verb) + 士 -shi becomes 讯士}

hùshì 'protector or person who works to keep others safe'.

All the personal meanings constructed by the suffix $\{\sim \pm-$ shi $\}$ together with the verb morpheme elements indicate a person who has the ability through the practice process and is still at the level of a trained personal. This means that the personal meaning that is built can carry out verb element activities through the practice process and until it reaches a trained level. To form the specification of this personal meaning, it does not require the involvement of certain scientific and/or theoretical concepts. But, it emphasizes more on the aspect of forming a level of habituation or training as the main feature of personal meaning identity. 


\subsection{Suffix $\{\sim 工-g \overline{o n g}\}$}

The basic meaning of letter element (工 gōng) in the suffix $\{\sim 工-g \bar{o} n g\}$ actually means 'work'. This is a free morpheme in the form of a verb, but when it is used as a suffix, the meaning is lost and the type is also changed as a bound morpheme. The semantic function of the suffix $\{\sim$ 工 - gōng $\}$ forms a personal meaning with a specification of personal meaning who has a profession as a worker who prioritizes physical elements or manual labor. As a result, the element of verb morpheme that is followed is also a type of verb that has a basic meaning of activity which emphasizes more on physical use, not the type of activity that prioritizes logical aspects. From the following sample data, it can be proven how the character of personal meaning is constructed and how the types of verb elements are followed.

1). 劳 láo 'work' (verb) $+\{\sim$ 工 -gōng $\}$ becomes 劳工 láogōng 'blue-collar workers'.

2). 维修 wéixiū 'repair' (verb) + 工 -gōng becomes 维

修工 wéixiūgōng 'repairman'.

3). 刻 $k \grave{e}$ 'sculpt' (verb) + 工 -gōng becomes 刻工

kègōng 'sculptor'.

The first thing that can be noticed from the example above is the morpheme element of the verb which is followed by the suffix $\{\sim$ 工 $-g \bar{o} n g\}$. The basic meaning shared by all verb elements in the structure is a form of activity that emphasizes the impression of physical movement. This basic meaning character is evidence of conformity with the specification of the semantic function of the suffix $\{\sim$ 工 - gong $\}$, which is to form a personal meaning that is limited to the specification of hard workers and/or manual workers. Thus, the semantic function specification of the suffix $\{\sim$ 工 $-g \bar{o} n g\}$ serves to limit the types and characters of verb morpheme elements that can be followed by the suffix $\{\sim 工-g \bar{o} n g\}$.

\subsection{Suffix $\{\sim$ 兵 - bing $\}$}

The suffix $\{\sim$ 兵 - bing $\}$ has a clearer specification of semantic functions and the realm of meaning, namely to form a personal meaning that has a profession related to the military world. Therefore, the scope of the basic meaning of verb morphemes followed by the suffix $\{\sim$ 兵 - bing \} will be limited and brought to the direction of military-related meanings. As a result, the personal meaning that is built will also refer to the personal meaning of carrying out activities that have a relationship with the military world. As evidence, the following data examples can be considered.

1). 骑 qí 'ride' (verb) + 兵 - bìng becomes 骑兵 qíbīng 'cavalry'.

2). 闪 shăn 'move quickly' + 兵 - bing becomes 闪兵 shănbīng 'fast (army) force'.

3). 排头 páitóu 'line up in front' (verb) + 兵 - bing

becomes 排头兵 páitóubīng 'frontline soldiers'.

From the data above, it can be ascertained that the meanings constructed by the suffix $\{\sim$ 兵 $-b \overline{i n g}\}$ together with verb morpheme elements all produce personal meanings related to the military world. The basic meaning of the verb element becomes an attribute that marks and identifies each personal meaning so that the scope of personal meaning produced is limited by the basic meaning of the verb element.

\section{CONCLUSION}

The semantic function possessed by each suffix has varied behavior, namely there is one type of suffix that can refer to personal meanings that have a broad scope of meaning such as the suffix $\{\sim$ 者 $-z h e \breve{\}}$. The personal meaning formed by this suffix is still general in nature and does not yet have a clear identity. Thus, the specification of the personal meaning built by this suffix, the realm of its meaning is limited by the basic meaning of the verb element. As a result, the relationship between the suffix $\{\sim$ 者 $-z h \breve{e}\}$ and the verb element is open. This means that the suffix $\{\sim$ 者 $-z h \breve{e}\}$ is relatively more able to follow a variety of verb types. On the other hand, there are suffixes that already have a more specific semantic function, namely the scope of personal meaning that has been built has been limited and clearly identified. In this case, the suffix $\{\sim$ 兵 - bing $\}$ clearly limits the scope of personal meaning to the identity of the military field, and the suffix $\{\sim$ 工 $-g \bar{o} n g\}$ limits the scope of personal meaning built with the identity of manual workers. As a result, these two suffixes are more closed or special so that their relationship with the verb element is frozen. This means that the two types of suffixes can only follow certain verb elements, namely verb elements that have a basic meaning that is in accordance with the specifications of the personal meaning of each of the two suffixes. Meanwhile, although not as clear as the suffix $\{\sim$ 兵 $-b \overline{i n g}\}$ and the suffix $\{\sim$ 工 - gōng $\}$, the suffixes $\{\sim$ 师 -shī $\},\{\sim$ 员-yuán $\},\{\sim \pm-s h \grave{\imath}\}$, and $\{\sim$ 手 -shŏu $\}$ still clearer and narrower in scope of meaning when compared to the suffix $\{\sim$ 者 $-z h \breve{e}\}$. 


\section{REFERENCES}

[1] C. Xin, “新兴指人类词缀语法化中的主观化. 陕 西师范大学国际汉学院," Faculty of International Mandarin of Shaanxi Normal University, 2020. https://kns.cnki.net/kcms/detail/detail.aspx?dbcode $=\mathrm{CJFD} \&$ dbname $=\mathrm{CJFDLASN} 2020 \&$ filename $=\mathrm{XK}$ CD202025010\&v=YIGKrBBHkpHdR\%25mmd2F 4azh2WG\%25mmd2FYFd\%25mmd2BfLHePv08F CkHnX5iCXmL\%25mmd2F0g2pNqoYnPH7xLgL 0 (accessed Apr. 21, 2021).

[2] Q. Yán, “现代汉语指人类词缀研究及在教学中的 应用，”中央民族大学，2019. https://kns.cnki.net/kcms/detail/detail.aspx?dbcode $=$ CMFD\&dbname $=$ CMFD201902\&filename $=1019$ 202987.nh\&v=kLZI5LgvO7kMyN85\%25mmd2B6 OO893MDAy12FZ\%25mmd2F6GhOJrlbTwRUkV HfTMIeOQV1zYzFd0f3.

[3] S. Zhāng, “现代汉语新兴指人类词缀探究,” Shanghai Normal University, 2018. https://kns.cnki.net/kcms/detail/detail.aspx?dbcode $=\mathrm{CMFD} \&$ dbname $=\mathrm{CMFD} 201802 \&$ filename $=1018$ 028268.nh\&v=1OUb8L9xCq\%25mmd2FOM18cV 5R2maS6xCU7iy8rTZZzX0z2c7NayYPEeXHa\%2 5mmd2BqmUTtReL14z (accessed Jul. 10, 2021).

[4] Y. Wáng, “现代汉语指人类词缀研究 - 中国知网 ," Qinghai University for Nationalities, 2013. https://kns.cnki.net/kcms/detail/detail.aspx?dbcode $=\mathrm{CMFD} \&$ dbname $=\mathrm{CMFD} 201401 \&$ filename $=1013$ 351956.nh\&v=UvprLqtgMG\%25mmd2Fomh7Kbr vcd7kILt8zezFk4D0gOY65c41L59f9TO2eWiymtA 7omWbw (accessed Mar. 05, 2021).

[5] M. Utomo, “中高级印尼学生汉语指人词缀习得 情况研究 ,” 2014. https://kns.cnki.net/kcms/detail/detail.aspx?dbcode $=$ CMFD \&dbname $=$ CMFD201501\&filenme $=10155$ 23078.nh\&v=paLZdFZwLdq5TgVE6\%25 mmd2B CVrZBkCs2R9vTGw1yt6weZT\%25mmd2BClfkV Pc1jqJH3IiOxe2b7F (accessed Jul. 10, 2021).

[6] F. Yuqing, “实用汉语语法 Shiyong Hanyu Yufa (Gramatika Bahasa Mandarin Praktis)," Beijing: Beijing Yuyan Хueyuan Chubanshe, 1992.

[7] C. Y. Ren, "A grammar of spoken Chinese. Berkeley." Los Angeles: University of California Press, 1968.

[8] Y. Zhàn, “现代汉语指人类词缀的多维度考察.,” Heilongjiang University, 2015. https://kns.cnki.net/kcms/detail/detail.aspx?dbcode $=\mathrm{CMFD} \&$ dbname $=$ CMFD201601 $\&$ filename $=1015$ 373993.nh\&v=tbMe0R\%25mmd2Fd\%25mm $2 \mathrm{BK}$ CBUuphkK5VxJzAhWGubNsAAUnLaur1kq6pxd
YlWx6DuLmeH6N\%25mmd2Ff9gw

(accessed Mar. 05, 2021).

[9] Y. Fāng, “当代汉语贬义表人的类后缀研究,”西 南交通大学 ， 2019 https://kns.cnki.net/kcms/detail/detail.aspx?dbcode $=$ CMFD \&dbname $=$ CMFD202001\&filename $=1019$ 950247.nh\&v=xJtc1uhTnYgqYq4VbllGh5I2foXHn fLfzFmvkGUsaquZgfYja0SO6PaZ898zQcH7.

[10] Y. Shí, “汉语新词语类词缀研究,”Qufu Normal University, 2016. https://kns.cnki.net/kcms/detail/detail.aspx?dbcode $=\mathrm{CMFD} \&$ dbname $=\mathrm{CMFD} 201701 \&$ filename $=1016$ 148863.nh $\& \mathrm{v}=$ FyO6q $\% 25 \mathrm{mmd} 2 \mathrm{Bu} 0 \mathrm{a} 1 \mathrm{daGuQlTh}$ mhlqg5Jcrc\%25mmd2F0Q8frZG1\%25mmd2BogV 3BbAjkT\%25mmd2BpRYO0EbE8SD7blP (accessed Mar. 16, 2021).

[11] 劉正忠, “漢字詩學與當代漢詩: 從葉維廉到夏宇 ,’中山人文學報, no. 46, pp. 31-58, 2019. 